\title{
Risk mitigation of performance ratio guarantees in commercial photovoltaic systems
}

\author{
H.A. Basson ${ }^{1}$, J.C. Pretorius ${ }^{1}$ \\ ${ }^{1}$ Faculty of Engineering and the Built Environment \\ University of Johannesburg \\ Kingsway Campus - Auckland Park (South Africa) \\ Fax number: +27 11 5594947, e-mail: habasson@gmail.com,jhcpretorius@uj.ac.za
}

\begin{abstract}
This study demonstrates the importance of managing the risk of performance ratio guarantees, which typically are applicable to most commercial PV projects. A qualitative assessment of the performance metrics has shown multiple performance parameters, which could influence the Performance Ratio. Alternative performance metrics, including the Temperature Corrected Performance Ratio and the Weather Corrected Performance Ratio were evaluated by means of a quantitative analysis. The Temperature- and Weather Corrected Performance Ratios have both demonstrated the capability of reducing the inter-annual and seasonal variance experienced with the conventional Performance Ratio. The respective performance metrics were further calculated from multiple years of meteorological data in order to construct a statistical distribution for each performance metric. The resulting probability distribution function was then used to determine the probable risk percentiles for each of the respective performance metrics and compared with the separately calculated performance metrics referring to a long-term mean data set. It was demonstrated that the long-term mean derived performance parameters did present a risk for overstating the facilities' performance. The risk was mitigated by referring to the multi-year's P90 percentile instead.
\end{abstract}

\section{Key words}

PR Probability, Performance Ratio, Temperature Corrected Performance Ratio, Weather Corrected Performance Ratio.

\section{Introduction}

Performance Ratio (PR) guarantees are typical in Engineering Procurement and Construction (EPC) agreements for commercial photovoltaic (PV) power generation facilities. This ensures that the EPC contractor can be held liable for the facility's performance as originally proposed during the bidding stage. It theoretically provides comprehensive protection in solar $\mathrm{PV}$ projects against a wide range of risks [1]. It ensures that the EPC contractor has completed the project to specification prior to its acceptance by the owner [2, p. 3].

The contractor's liability for Performance Liquidated Damages (PLDs) could typically be set at $20 \%$ of the overall EPC price, but failure to remedy the underperformance, could result in breach of the contract, which carries the maximum liability of contract termination, plus reinstatement [3, p. 13].

The Performance Ratio guarantees required from EPC's very seldom define the measuring season of the PR compared to the guaranteed annualized PR [3, p. 49]. Research has shown that the weather effect on the PR can result in a seasonal variance of up to $10 \%[4, \mathrm{p}$. 1]. The stakeholders require a level of confidence for the expected facility output, based on quality and uncertainty of the inputs used for the yield calculation model. Similarly, the liable party should have some level of confidence in providing a PR guarantee.

The objective of this study is threefold:

- Determine which alternative PR calculation can be used to reduce the sensitivity to the meteorological variability;

- Qualify the influencing parameters to reduce variability of the PR and

- Quantify the probability of achieving each of the respective PR's presented.

\section{Literature Survey}

A qualitative survey was done, focusing on the risk categories associated with the PV facility life cycle, different performance metrics, followed by data variability in the simulations stage.

\section{A. Performance Calculation}

Ransom summarized some of the uncertainties affecting the performance ratio as indicated in Table 1 below $[5, \mathrm{p}$. 2].

Applying the Central Limit Theorem, Ransom has shown that at best, the PR measured between different sites can differ by $6 \%$, mostly due to uncertainties of the irradiance sensor and the annual irradiance variability [5, p. 2]. The same would apply for determining the PR for any new project. Research conducted for this study has found 
three options of determining the performance ratio metric.

Table 1. Uncertainties affecting the PR [5, p. 2]

\begin{tabular}{|l|l|l|}
\hline VARIABLE & $\begin{array}{l}\text { FOR } \\
\text { DIFFERENT } \\
\text { SITES }\end{array}$ & $\begin{array}{l}\text { FOR THE } \\
\text { SAME } \\
\text { SITE }\end{array}$ \\
\hline $\begin{array}{l}\text { Availability, Inverter Loss, } \\
\text { PV Module performance }\end{array}$ & Unknown & Unknown \\
\hline Soiling & $\pm 1 \%$ & $0 \%$ \\
\hline $\begin{array}{l}\text { Irradiance Sensor } \\
\text { Calibration }\end{array}$ & $\pm 2 \%$ & $0 \%$ \\
\hline Yearly insolation variability & $\pm 4 \%$ & $0 \%$ \\
\hline $\begin{array}{l}\text { Reference Module } \\
\text { calibration }\end{array}$ & $\pm 2 \%$ & $\pm 2 \%$ \\
\hline Module power class & $\pm 2.5 \%$ & $\pm 2.5 \%$ \\
\hline Degradation & $<-1 \% / y$ & $<-1 \% / y$ \\
\hline
\end{tabular}

1) Performance Ratio. The PR is the conventional performance metric as defined by the International Electrotechnical Commission (IEC) as follows [6, pp. 1-2], [7, p. 14], [8, p. 18]:

$$
\begin{gathered}
P R=Y_{f} / Y_{r} \\
Y_{f}=E_{A C} / P_{O} \\
Y_{r}=\tau_{r} \times\left(\Sigma_{\text {day }} G_{I}\right) / G_{I, r e f}
\end{gathered}
$$

Where: $E_{A C}$ is the energy measured at the delivery point expressed in $\mathrm{kWh} ; P_{O}$ is the DC output power at Standard Test Condition (STC) expressed in $\mathrm{kW}_{\mathrm{P}} ; \tau_{r}$ is the recording interval in hours; $G_{I}$ is the in-plane irradiation expressed in $\mathrm{kWh} / \mathrm{m}^{2}$ and $G_{I, r e f}$ is the reference in-plane irradiance, equal to $1 \mathrm{~kW} \cdot \mathrm{m}^{-2}$.

A theoretical model was developed for System 3 at the TEP Solar Test Yard in Tucson, Arizona and was calibrated by referring to the system performance data measured in 2013 [9].

For purpose of demonstration, the hourly PR was calculated based on the hourly meteorological data contained in the long-term mean data set obtained from Meteonorm 6.1 and the performance results obtained from the system simulation in PVsyst 6.35 [10]. As shown in Figure 1 (Top), the PR exhibits a seasonal variability, which contributes to performance risk during acceptance testing $[11, p .3],[4, p .1]$.

2) Temperature Corrected Performance Ratio $(T C P R)$. The TCPR incorporates a temperature correction factor in the PR ratio. The following PR calculation method was obtained from sample contractual clauses used recently in South Africa [3, pp. 45-48]:

$$
\begin{aligned}
& P R_{T C}=Y_{f} /\left(Y_{r} \times T C \times D\right) \\
& T C=1-\delta\left(T_{\text {ref }}-T_{\text {real }}\right) \\
& D=(1+D F)^{n} \times D F_{\text {final }}
\end{aligned}
$$

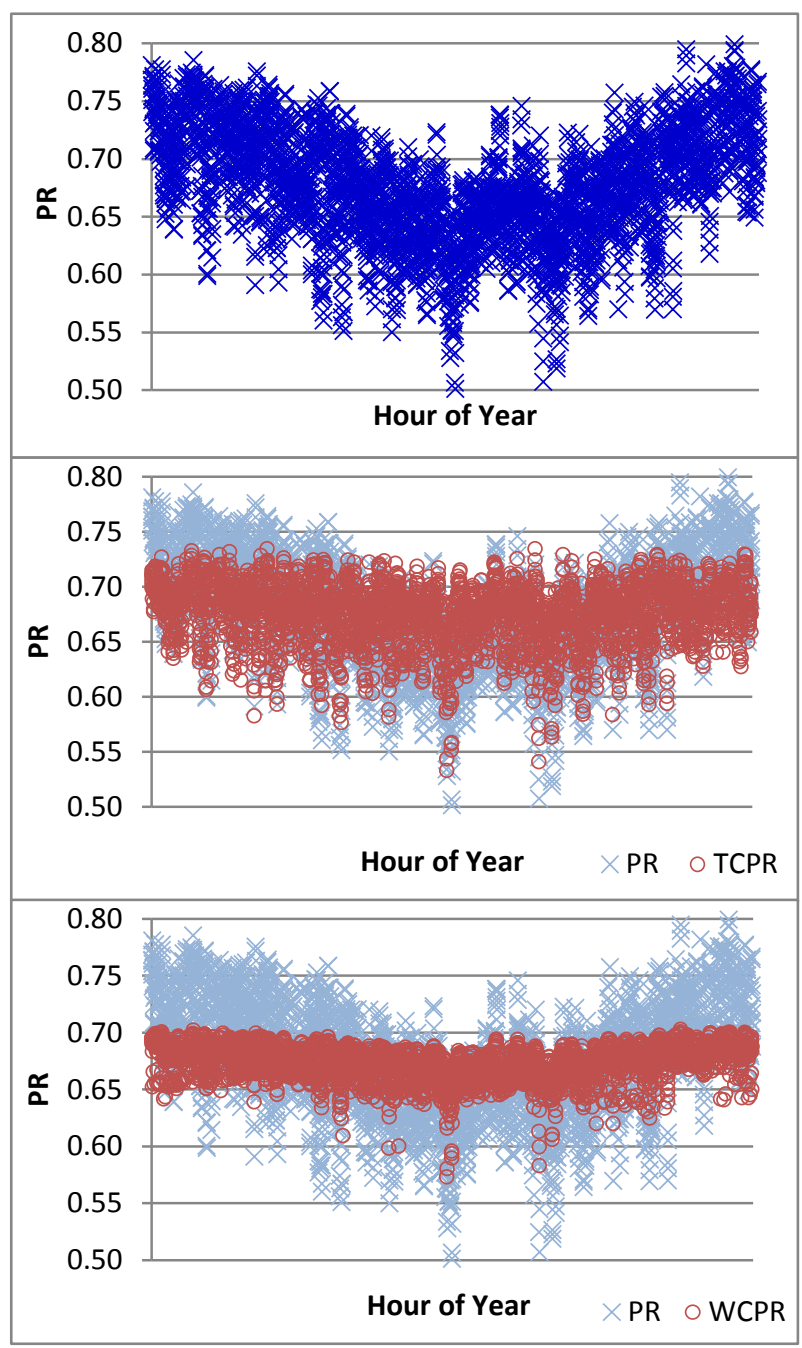

Figure 1. Variance of hourly PR (Top), TCPR (Middle) and WCPR (Bottom) over a period of one year

Where [3, pp. 45-48]: $T C$ is a dimensionless temperature correction factor; $\delta$ is the temperature coefficient, a negative number expressed in $\% /{ }^{\circ} \mathrm{C}$; T_ref is the reference temperature expressed in ${ }^{\circ} \mathrm{C}$; T_real is the measured average temperature; $D$ is a dimensionless degradation correction factor; $D F$ is the annual degradation specified by the module supplier; $n$ is the number of years following the commercial operation date and $D F_{\text {final }}$ is the degradation factor at the end of the evaluation period.

Similar to the PR discussed previously, the hourly TCPR was calculated based on the longterm mean data set and presented in Figure 1 (Middle). It is observed that the introduction of the temperature correction does have a positive effect in reducing the seasonal variance.

3) Weather Corrected Performance Ratio (WCPR). The PV module temperature is determined by a thermal energy balance directly related to the ambient temperature as well as a thermal loss factor, which has a variable component dependant on the wind speed [12], [10]. The 
WCPR incorporates the effect of wind in the performance metric. The following calculation method has been extracted from the studies done by Dierauf et al [4, pp. 11-15].

$$
\begin{gathered}
P R_{W C}=\frac{\Sigma_{i} E_{A C_{-} i}}{\Sigma_{i}\left[P_{O}\left(G_{I i} / G_{I, r e f}\right) \times T C_{i}\right]} \\
T C_{i}=1-\delta\left(T_{\text {cell_typ_avg }}-T_{\text {cell_i } i}\right) \\
T_{\text {cell_typ_avg }}=\Sigma\left[G_{P \text { OA_typ }_{-} j} \times T_{\text {cell_typ } j}\right] \\
/ \Sigma\left[G_{P O A_{-} t y p_{-} j}\right] \\
T_{\text {Cell }}=T_{m}+\left(G_{I} / G_{S T C}\right) \times \Delta T c n d \\
T_{m}=G_{I} \times h+T_{a} \\
h=\exp (a+b \times W S) \\
E N_{D C i}=P_{O}\left(G_{I i} / G_{I, r e f}\right) \times T C_{i} \times t_{i} \\
P R_{W e a t h C o r r}=\Sigma_{i} E N_{A C i} / \Sigma_{i} E N_{D C i}
\end{gathered}
$$

Where [4, pp. 11-15]: $T_{\text {cell_i }}$ is the cell temperature computed from the meteorological data; $T_{\text {cell_typ_avg }}$ is the average irradiance-weighted cell temperature in one year of the project weather file; $T_{\text {cell_typ_j }}$ is the calculated cell temperature per hour; $j$ is each hour of the year; $T_{m}$ is the PV module's back-surface temperature expressed in ${ }^{\circ} \mathrm{C} ; h$ is the convection heat transfer coefficient expressed in ${ }^{\circ} \mathrm{C} \mathrm{m}^{2} / \mathrm{kW}$; $a$ is an empirical constant for temperature increase due to sunlight presented in Table 5 below; $b$ is an empirical constant for effect of wind speed; WS is the measured wind speed, corrected to a height of ten meters, expressed in $\mathrm{m} / \mathrm{s}$ and $\Delta T c n d$ is the conduction temperature drop.

Similar to the PR and TCPR discussed previously, the hourly WCPR was calculated based on the long-term mean data set and presented in Figure 1 (Bottom). It is observed that the introduction of the temperature correction and normalisation with the average module cell temperature does have a significant effect in reducing both the seasonal variance and short term hourly variance compared to the conventional PR.

The following section will discuss the respective performance parameters which can contribute to the variance and the resulting uncertainty of the performance ratio metric in general.

\section{B. Variation of the Performance Ratio}

1) Measurement Uncertainty and Inaccuracy. Although some meteorological databases combine satellite derived data with ground measured meteorological data, these models inherently still contain uncertainty due to the different atmospheric states such as cloud cover, aerosols or water vapour $[13, p .2],[14, p .5]$.

A study indicated that high quality pyranometers can have a typical error between $-10 \%$ to $2.5 \%$ and perheliometers, which are slightly more accurate, can expect a typical error ranging between -2.5 to $2.5 \%$ [15, p. 1080].

2) Inter-annual Variability and Representativeness of the Monitoring Period. A study by Pitz-Paal et al. indicated that 7 to 10 years of measurements are required to reduce the deviation to the long-term mean within $5 \%$ [16, p. 7]

It is observed from Pitz-Paal's study that the commercially available long term mean data sets, such as Meteonorm, would inevitably also generally have a deviation within $5 \%$, which is good for long term yield forecasts, but not good at all for determining the real minimum and maximum meteorological thresholds that would directly influence the PR for that particular evaluation period.

3) Transposition to Plane of Array. In order to calculate the energy conversion of the solar PV model, the irradiance needs to be adjusted for the amount of incident irradiance that will reach the solar Plane of Array (POA), known as the Direct Normal Irradiance (DNI) [17, p. 434]. This transposition introduces a further margin of error in the order of $2-5 \%$ [18, pp. 7-8].

4) Simulation. Studies by Thevenard et al. [17, $p$. 436] and Schnitzer [18, pp. 7-8] indicated that a typical, well-defined model still has an expected uncertainty of 3 to $5 \%$. Other than the meteorological data discussed before, the single highest remaining uncertainty during simulation is contributed by the validity of the PV Module's performance characteristics represented in the theoretical model [12, p. 15]. The PV modules form a majority of the capital investment, thus for the purpose of improving the PR, the manufacturer and module selection is a key risk mitigation strategy and well worth the extra effort.

5) DC to AC conversion efficiency. The inverter's electrical configuration has both an effect on the overall efficiency of the PV system as well as the reliability. There are three main inverter configurations that can be considered for the electrical design [19, p. 229]: Centralized inverter with multiple DC inputs on a single DC bus; Parallel inverters with separate DC busses and lastly Parallel inverters with a common DC bus. A case study by $\mathrm{He}$ et al. revealed that the parallel configuration with a common DC bus can improve the inverter system performance ratio by up to $1.5 \%$, compared to a single central inverter [19, p. 333].

6) Thermal Derating Loss. The efficiency of a PV module is directly affected by the cell temperature, decreasing in efficiency as the temperature rises. The reduction in efficiency 
can be calculated as a function of the temperature coefficient, which is published in the PV module's technical specifications and the module temperature [12, p. 11]. The PV module temperature is determined by the energy balance between the ambient temperature and the internal cell temperature due to the incident irradiance and the cell efficiency [10]. It is this relationship that contributes to the sensitivity of the performance ratio to the meteorological conditions and resulting seasonal variance.

\section{Probability}

Two separate studies by Dobos et al. [20, p. 3] and Thevenard et al. [17, p. 440] respectively determined the probabilistic irradiance and yield by using an empirical CDF constructed by simulating the yield for multiple meteorological years. Dobos et al. has shown that the empirical CDF for the GHI and resulting system yield can be compared with the CDF of a Normal distribution [20, p. 3].

The case study below will utilize the same method to determine the statistical distribution of the monthly PR.

\section{Case Study: Simulation of a PV facility for PR calculation}

The following sections will demonstrate the statistical variability of the PR, TCPR and WCPR by performing multiple simulations using the calibrated theoretical model discussed previously and each meteorological year between 1961 and 1990, which were obtained from the National Solar Radiation Database (NSRDB) [21].

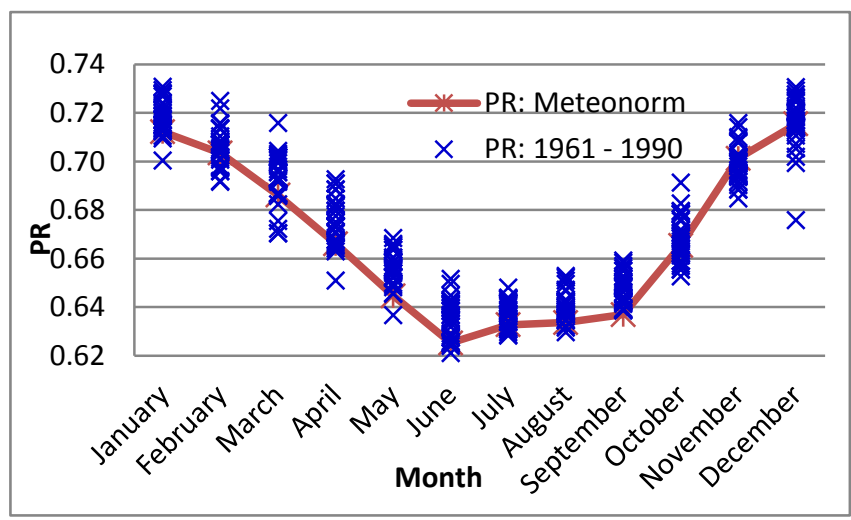

Figure 2. Monthly PR calculated for System 3, TEP solar yard, Tucson, AZ

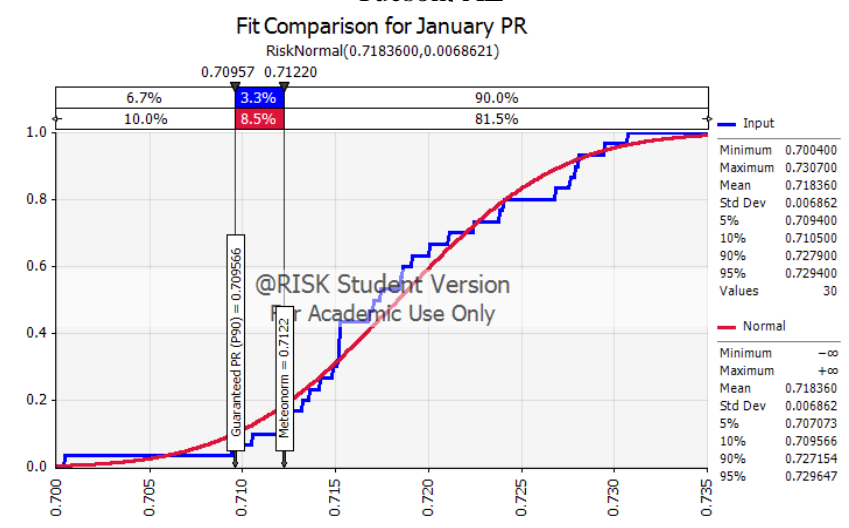

Figure 3. CDF of PR calculated for January, 1961 to 1990

\section{A. Probability distributions for $P R$}

Figure 3 indicates the monthly PR calculated for System 3 at the TEP Solar Test Yard in Tucson, Arizona utilizing the previously discussed calibrated theoretical model and referring to multi-year NSRDB and long-term mean meteorological years respectively.

The multiple PR's calculated for each month, creates a statistical distribution, as indicated by the empirical Cumulative Distribution Function (CDF) for the January PR values in Figure 2. Similar to the representation of the statistical yield by Thevenard [17], the statistical distribution of the PR has been presented as a Normal (Gaussian) CDF. The P90 value, with $90 \%$ chance of achievement, can be calculated from the CDF, indicated here as a PR of 0.70957. Given the CDF of the PR, the probability of achieving the long-term mean PR for January can be calculated as well. For this example, the month of January would have an $81.5 \%$ probability of achieving the expected PR calculated from the long-term mean data set.

The top graph in Figure 4 summarizes the probabilistic PR for each month, based on the 30-year simulations. Each bar indicates the P95, P90, P10 and P5 thresholds, compared to the long-term mean PR.

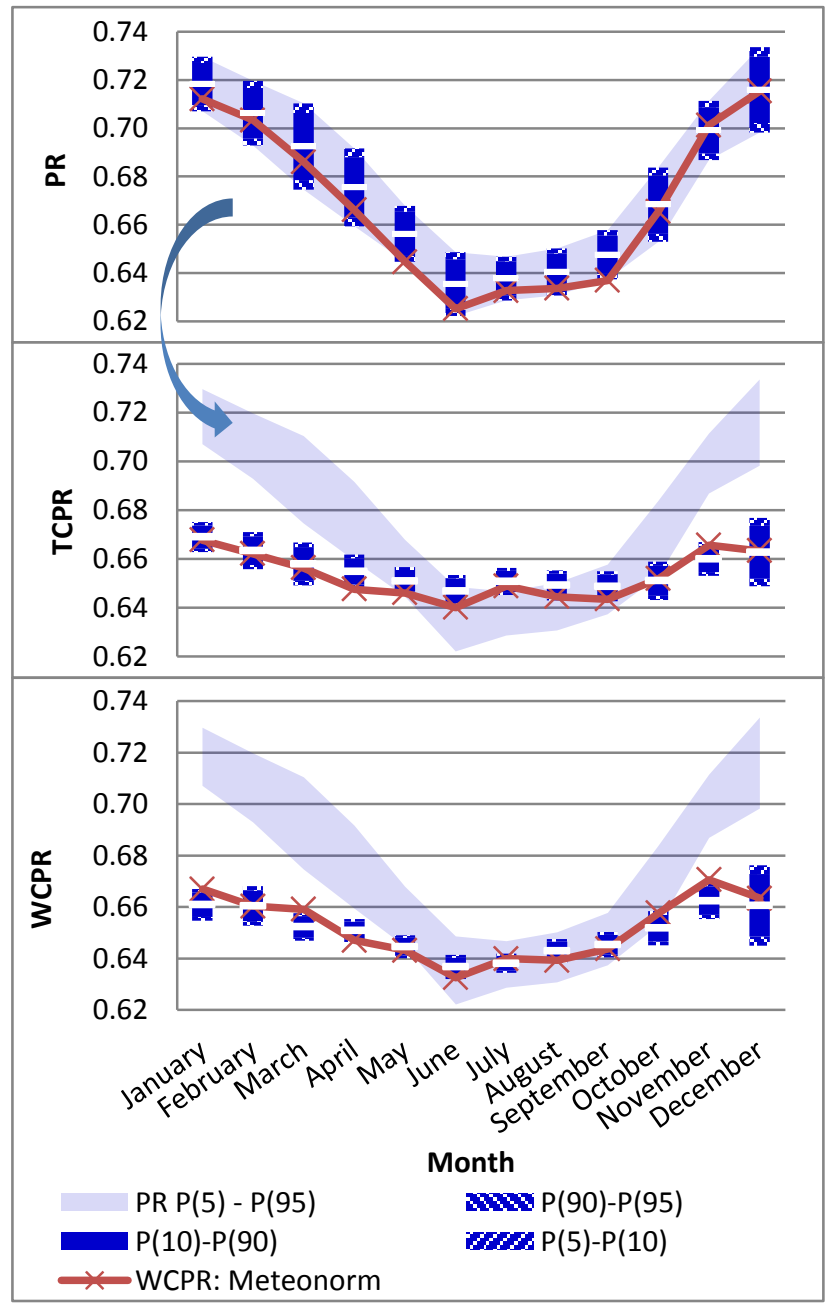

Figure 4. Probable PR (Top), TCPR (Middle) and WCPR (Bottom) ranges compared to long term Mean 


\section{B. Probability distributions for TCPR}

Similar to the multi-year simulations done for the PR, the TCPR is presented in Figure 4. It is observed that the TCPR significantly reduces the seasonal- and inter-annual variance, compared to the conventional PR shown in the shaded area for ease of reference.

\section{Probability distributions for WCPR}

The bottom graph in Figure 4 indicates the probabilistic WCPR for each month. It is observed that the introduction of the temperature correction and normalisation with the average module cell temperature does have a significant effect on the seasonal- and inter-annual variance, compared the conventional PR and has a slightly lower variance compared to the TCPR.

Figure 5 shows a summary of the quantitative analysis of the respective performance metrics in this study. First, the theoretical model was developed and calibrated with reference to the measured meteorological- and system yield records for one specific reference year. The same model was then used to determine the PR for each month from 1961 till 1990 by referring to the NSRDB meteorological data set. The long-term mean data set from Meteonorm were used to calculate the expected PR, which typically would form the basis of the guaranteed PR. The multi-year PR values presented a statistical distribution, from which the probabilistic PR, TCPR and WCPR could be determined.

\section{Conclusion}

The introductory section established a need to determine the risk associated with performance guarantees for solar PV projects. It was determined that the performance ratio is a well-defined performance metric, which has been standardized in the industry.

The qualitative research stage has presented numerous performance parameters that can influence the performance ratio metric, the most influential summarized as follows:

1) Measurement uncertainty;

The advantages of long-term satellite derived data have been presented and its importance established for a reliable meteorological data set.

2) Inter-annual variability;

The long-term mean data set has been demonstrated as a very reliable resource estimate for long term yield estimations. However due to its long term averaged nature, the reduced minimum and maximum deviations is obscuring the risk of underperformance for individual time periods under review. The study made reference to separate studies which had made use of a multi-year simulation process to construct a statistical distribution of the system yield.

3) Simulation;

It was concluded that PV module performance models need to be validated by reputable third parties and since the PV modules forms a significant part of the capital investment, its due diligence is worth the extra effort.

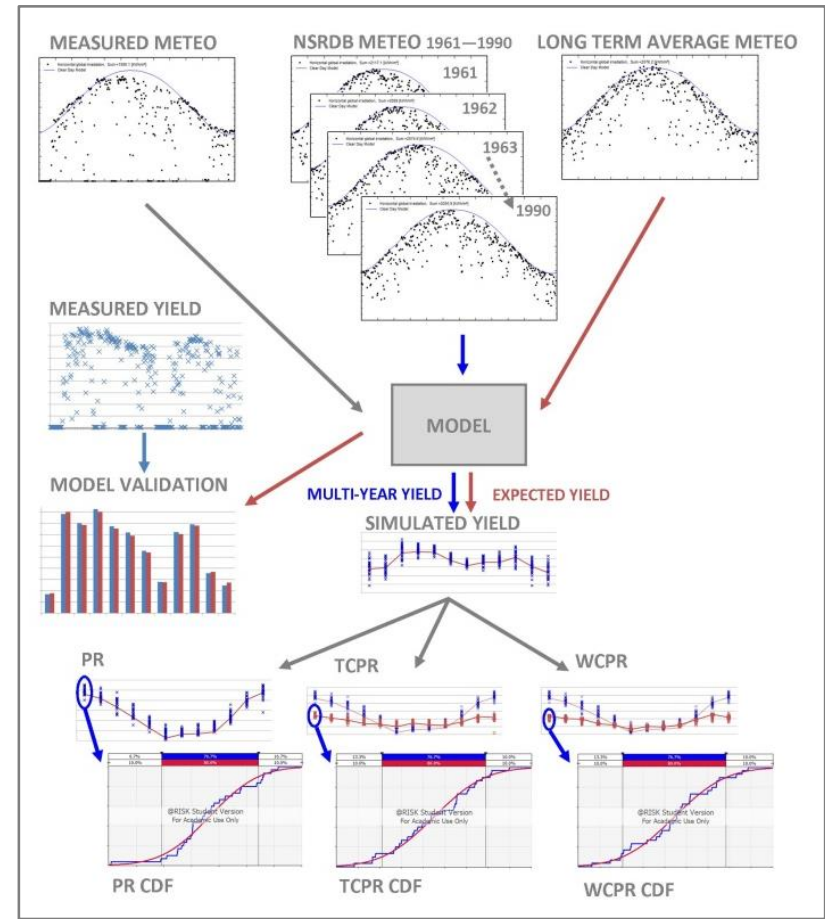

Figure 5. Overview of quantitative analysis of PR, TCPR and WCPR performance metrics

4) DC to AC conversion efficiency and

The different inverter configurations were evaluated for both efficiency and reliability. It was demonstrated that the parallel inverter configuration with a single DC bus would be most beneficial for both efficiency and reliability.

5) Thermal derating.

The PV module's performance sensitivity to temperature is pivotal in the risk mitigation demonstrated by the respective performance ratio metrics discussed in this study. It was shown that the PV module temperature is governed by an energy balance between external energy being applied through the solar irradiance and the PV module's capability to convert this to useful energy, which is electrically extracted. The balance of energy is shed as heat.

The quantitative analysis stage of the research involved a multi-year simulation to construct a statistical distribution of the system yield and performance. A Normal distribution was used to represent the probability distribution of the respective yearly data sets, for each month and for each type of performance ratio calculation. The probability was quantified for achieving the performance metrics, which were calculated with a longterm mean data set from Meteonorm. The case study demonstrated the quantified risk of not achieving the respective PR, TCPR and WCPR's which were calculated with the long term mean data set.

It is observed that although the respective TCPR and WCPR do reduce the variance caused by the meteorological conditions, the corrected PR metric, on its 
own, is not a sufficient mitigation against a performance guarantee.

By further evaluating the statistical distribution of the multi-year simulation done, the P90, P95, P10 and P5 probabilistic values were determined. The PR, TCPR and WCPR, which were calculated from the long-term mean data set was compared with the multi-year statistical results, which indicated a risk of not achieving the longterm mean derived performance metrics. In order to reduce the probability of underperformance, the mitigated performance guarantees were constructed by referring to the P90 values of the multi-year simulation instead.

\section{Acknowledgement}

Thank you Dirk Jordan (National Renewable Energy Laboratory, Golden, Colorado, USA), Didier Thevenard, (Canadian Solar O\&M Inc. Ontario, Canada) and Alexander Cronin (Department of Physics, University of Arizona, Tucson, USA).

\section{References}

[1] D. Schroeder and E. Cullen, "Risk Protection For Midsize Solar Installations," Solar Industry, vol. 6, no. 1, February 2013.

[2] J. Meydbray, R. O'Connell and A. T. Braff, "Hot Issues in PV Performance and Solar Project Finance," October 2012. [Online]. Available: https://www.wsgr.com/publications/PDFSearch/braf f-103112.pdf. [Accessed 10 January 2015].

[3] K. Whyte and D. McNair, "EPC Contracts in the Renewable Energy Sector - South African RE IPP Programme - Lessons Learned from Phases 1 and 2," October 2012. [Online]. Available: http://www.dlapiper.com/files/Publication/958e6736 -27 df-42ae-9f5f-

a0cffe $7 \mathrm{e} 5 \mathrm{fcd} /$ Presentation/PublicationAttachment/0 d63553d-dbfe-49e7-8f18-c01e6bcac7e0/epccontracts-renewable-energy-south-africa-2.pdf. [Accessed 10 March 2014].

[4] T. Dierauf, A. Growitz, S. Kurtz, J. L. B. Cruz, E. Riley and C. Hansen, "Weather-Corrected Performance Ratio," National Renewable Energy Laboratory, Golden, 2013.

[5] S. Ransome, "Modelling inaccuracies of PV energy yield simulations," IEEE, New York, 2008.

[6] B. Marion, J. Adelstein, K. Boyle, H. Hayden, B. Hammond, T. Fletcher, B. Canada, D. Narang, D. Shugar, H. Wenger, A. Kimber, L. Mitchell, G. Rich and T. Townsend, "Performance Parameters for Grid-Connected PV Systems," National Renewable Energy Laboratory, Golden, 2005.

[7] International Electrotechnical Commission, IEC 61724 Photovoltaic system performance monitoring - Guidelines for measurement, data exchange and analysis, 1st ed., Geneva: International Electrotechnical Commission, 1998.

[8] D. Jordan, "Methods for Analysis of Outdoor
Performance Data," in 2011 Photovoltaic Module Reliability Workshop, Golden Colorado, 2011.

[9] A. Cronin, "University of Arizona Photovoltaics Download Historical UAPV Datasets," 2013. [Online]. Available: http://www.uapv.physics.arizona.edu/dlpvdata.php. [Accessed February 2015].

[10] Institute of the Sciences of the Environment, University of Geneva, "PVsyst V6.35," PVsyst SA, Geneva, 2015.

[11] S. Mau and U. Jahn, "Performance analysis of gridconnected PV systems," International Energy Agency, Köln, 2006.

[12] A. Mermoud, "Modeling Systems Losses in PVsyst," in 2013 Sandia PV Performance Modeling Workshop, Santa Clara, CA, 2013.

[13] T. Stoffel, A Review of Measured/Modeled Solar Resource Uncertainty, Santa Clara, CA: National Renewable Energy Laboratory, 2013.

[14] T. Stoffel, D. Renné, D. Myers, S. Wilcox, M. Sengupta, R. George and C. Turchi, "Concentrating Solar Power: Best Practices Handbook for the Collection and Use of Solar Resource Data," National Renewable Energy Laboratory, Golden, 2010.

[15] J. S. Stein, C. P. Cameron, B. Bourne, A. Kimber, J. Posbic and T. Jester, "A Standardized Approach to PV System Performance Model Validation," in $P V$ Specialists Conference, 2010 35th IEEE, Honolulu, 2010.

[16] R. Pitz-Paal, N. Geuder, C. Hoyer-Klick and C. Schillings, "How to get bankable meteo data? DLR solar resource assessment," Deutsches Zentrum fur Luft- und Raumfahrt, Cologne, 2007.

[17] D. Thevenard and S. Pelland, "Estimating the uncertainty in long-term photovoltaic yield predictions," Solar Energy, no. 91, pp. 432-445, 2011.

[18] M. Schnitzer, Reducing Uncertainty in Solar Energy Estimates A Case Study, Santa Clara, CA: Sandia National Laboratories, 2013.

[19] F. He, Z. Zhao and L. Yuan, "Impact of inverter configuration on energy cost of grid-connected photovoltaic systems," Renewable Energy, vol. 41, pp. 328-335, 2012.

[20] A. Dobos, P. Gilman and M. Kasberg, "P50/P90 Analysis for Solar Energy Systems Using the System Advisor Model," in 2012 World Renewable Energy Forum, Denver, Colorado, 2012.

[21] National Renewable Energy Laboratory, "National Solar Radiation Data Base 1961 - 1990: Typical Meteorological Year 2," [Online]. Available: http://www.rredc.nrel.gov/solar/old_data/nsrdb/. [Accessed March 2015]. 